\title{
The Immune Overreaction Phenomena in Severe Sars-cov-2 Human Infections
}

\author{
Ibrahim .M.S.SHNAWA \\ Department of Anesthesia, Hilla University College, Rarengia,Babylon Province, IRAQ
}

\begin{abstract}
The immunology of Sars-cov-2 human infection is known to be complex. One of the facets of its complexity is the occurrence of immune over reaction phenomena in its severe forms. Such forms stands as a challenge for laboratory diagnostics and clinicians due its further complexity. The objective of the present mini-review was to explore these immune over-reaction phenomena [IORP ] among the severe infection forms .The noted IORP in severe covid-19 were as; two,the innate immno-thrombi [microthrombi] and the hyper-cytokine-mia[cytokine storm],one cross-road IORP as an unrestrained activation of complement system and two adaptive IORP as an autoimmune phenocopy[ Neutralizing autoantibody producing B cell autoimmune pheno-copy of the type I Interferons ] as well as the Viral sensor [ Dynamics of the MAIT immune cells ]. These phenomena are resolved on reaching the possible case recovery.
\end{abstract}

Keywords: Adaptive ,cross-road ,innate ,immune ,over-reaction, phenomena ,sars-cov-2.

DOI: $10.7176 / \mathrm{JHMN} / 85-09$

Publication date: January $31^{\text {st }} 2021$

\section{Introduction}

In general ,the immune over-reaction phenomena IORP following disease conditions in man are; Five hypersensitivity types[I-V],Graft versus host reactions[GVHR],immune mediated disease conditions as well as the hemolytic disease of new born[HDNB] ( Abbas et.al.2015). In Sars-cov-2 human severe infection forms, the primary tropism of the virus in lung then kidney and brain. In lungs, however, preferred tissue cells are the epithelia in which the virus mediate alveolar damage through endothelial injury resulting in cytokine release, recruitment of immune cells and activation of coagulation and thrombosis in lungs then extends to other organs( Miyazawa 2020,Huang et al.2020). The status of sars-cov-2 severe infection appear to be somewhat different from the general known IORP. The objective of the present opinion was to disclose the nature of IORP in sever Sars-cov-2 human infection forms.

\section{Theme}

The basic theme upon which this min-review was built on was the nature of the immune response and cellular origin involved in these phenomena as in Table-1.The usual immune responses were stated. Then each phenomenon described as ; the nature of cell mediating the phenomenon, the core concept and current studies, the basic immune features and the workable gold standard marker helpful for its determination.

Table 1. Immune Over-reaction phenomena in sever Sars-cov-2 infection

\begin{tabular}{|l|l|l|}
\hline Nature of the immune response & Cellular origin & Phenomena \\
\hline Natural[innate] immune response & $\begin{array}{l}\text { Neutrophils } \\
\text { Immune cells }\end{array}$ & $\begin{array}{l}\text { Immune-thrombi } \\
\text { Cytokine storm[Cytokinemia] }\end{array}$ \\
\hline Cross-road & Hepato,entero, \& splenocyts & $\begin{array}{l}\text { Unrestrained } \\
\text { Activation[complement system] }\end{array}$ \\
\hline Adaptive immune response & B cells & $\begin{array}{l}\text { autoimmune pheno -copy[B cell } \\
\text { producing neutralizing anti-type I } \\
\text { interferons autoantibodies }\end{array}$ \\
& T cells & Viral Sensor[MAIT-dynamics] \\
\hline
\end{tabular}

\section{Immune reactions To Sars-cov-2 Virus Infection}

The virus induced B cell to produce IgM then class switched to $\operatorname{IgG}$ and IgA with in seven to 14 days for IgM,14 up to three weeks for IgG(Stephens \& McElrath 2020). The anti-spike protein neutralizing antibodies lasts for 6 months(Figueiredo-Campos, et al.2020). Memory B and T cell lasts for 6-8 months after the onset. The antibody and $\mathrm{T}$ cell (Sherina et al.2020)immune efficacy still a matter of debate and needs to elucidated. The standard immunodiagnostic tests are viral specific antibody and antigen detection. While, the standard molecular diagnostic tests are the nucleic acid tests(ECDPC,2020). 


\section{Natural Cellular Immune Over Reactions}

\subsection{Neutrophils}

4-1-1: Immuno-thrombi[microthrombi];

Neutrophils are the white blood cells having multi-lobe nuclei ranged from 2-6 lobes. Each lobe connected to the other by string of nuclear material. Chromatin is aggregated in their nuclei with neither evidence for DNA replication nor for DNA repair processes. The cytoplasm contained large amount of granules with finely structured endoplasmic reticulum, few polyribosome and scanty protein synthesis operating in these sort of cells. Neutrophils contained large amounts of glycogen. The main source of energy in resting state is glycolysis .While during phagocytosis metabolism made through hexose monophosphate cycle. As a cell ,neutrophil has microtubule network ,some of these tubules extend to the plasmic membrane . The net is important in guiding phagocyte movement. It represents the dominant cells in human peripheral blood stream. Neutrophils are the first liner in the inflammatory sites. They performed an array of natural cellular immune functions like; exocytosis, extracellular killing, antigen processing and presentation and phagocytosis(Dale \& Foreman 1984,Abbas et al.2015).As well as NETosis [immune-thrombi] formation (Middleton et al.2020,Zuo et al.2020). Immunethrombosis constitute the direct interaction of activated complement with platelets and coagulation factors in the innate immune response may contribute the thrombotic events described in covid-19 patients with coagulopathy(Manne et al.2020).Such pathogenic immune-thrombosis may be an outcome of the dys-regulated neutrophil extracellular traps(NET) formation in covid-19(Bames et al.2020). Neutrophil leukocytes produce NETs regulated cell death process known as NETosis(Fuchs et al.2007). The biochemical basic nature of NETs are; Extracellular 3 dimensional lattices of de-condensed chromatins decorated with histones ' and antimicrobial proteins are released upon stimulation with respiratory virus like sars-cov-2 which induce NETosis leading to NETs that physically trap and kill the virus as a part of an innate natural immune mechanisms(Middlton et al.2020,Schonrich \&Raftery ,2016 ).Platelets can trigger NETosis leading to a dys-regulated NETosis which in turn mediate tissue damage, hypercoagulability and thrombosis. (Fuchs et al.2010).Dys-regulated NETosis is associated with acute and chronic inflammatory diseases(Bonaventura et al.2018).Increase of NETs formation correlate with covid-19 acute respiratory distress syndrome and be a potential marker of the disease severity(Middleton et al.2020).Covid-19 sera have elevated levels of cell free DNA ,myelo- peroxidase-DNA and citrullinated histone H3. These three biochemical compounds are specific markers of NETs. Absolute neutrophil count correlate with cell free DNA, citrullinated histone H3,D dimer and lactate dehydrogenase(Zue et al.2020). 4-1.2 Immune Features of Immunothrombi

The basic immune features are;

- Neutrophils are the basic source of the mediators.

- Neutrophils normally release extracellular DNA net to kill the body invaders.

- Sars-cove-2 induce dys-regulation to the DNA net ,the NETosis.

- Platelets triggers the coagulation mechanisms .Thus ,thrombi formed

- NETosis is a marker of sars-cov-2 infection severity

- $\quad$ Plasma cell free DNA,Plasma cell free Myeloperoxidase -DNA,D dimer, citrullinated histone -3 are the basic markers of NETosis

4-1.3 Workable Molecular Determination Markers

Plasma D-Dimer.

\section{4-2: Natural Cellular Immune Over reactions}

4-2-1: Cytokine storm [Hypercytokinemia];

Cytokines are secretory hormone like peptides , synthesized and secreted from; immune, epithelial , and adipose cells, following an inducing stimulants. They are secreted during immune and overt immune as well as inflammatory reactions. Cytokine classified in accordance with the producing cell into monokines from monocytes and lymphokines from lymphocytes. They functions in; cellular signal transduction, and cell-cell signaling .In addition to the regulation of cellular growth, inflammatory and immune reactions. There is a harmony in functioning between cytokine production, release of endocrine hormones and neurotranssmitors. The immune system has a memory and education function that depends on cell-cell communication through mediators, receptors and transduction net lending chance for inter-system communications(Abbas et al.2015).

Hypercytokinemia is a severe immune reaction in which the body release too many cytokines into the blood so quickly. Cytokines play an important role in the normal immune responses, but having a large amount of them released into the body all at once can be harmful .Hyper-cytokinemia can occur as a results of; an infection, autoimmune conditions, and other diseases. It may also occur after treatment with some types of immunotherapy.It manifest high fever, inflammatory heat, redness, severe fatigue and nausea. Hypercytokinemia may be severe and life threatening and lead to multiple organ failure(NCI Dictionaries 2020).

Sars cov-2 human infection induce the synthesis of the natural[innate] cytokine responses by an array of target cells from monocyte-macrophage and neutrophils series into the focal site of infection (Badawi,2020,Duque 
\&Descotoaus 2014). The accumulation of these cells in the lung and blood vessel walls mediate inflammatory reactions to clear the focus of the infection and further synthesis of cytokines to stimulate immunity paired with an outcome of hypercytokinemia(He et al.2006,Ding et al.2004,Ying et al.2014).Such local cellular and excess cytokine release aggravate the lung and vascular tissue microenvironments leading to tissue injuries, lung exudates ,pulmonary edema, hyaline membrane formation and mucous cell activation to block the airways, ultimately manifesting ARDS(Xia et al.2020). The early stages of this process is paired with extensive lymphocyte apoptotic cell death that attenuate the cellular immune system leading to immune-deficiency (He et al.2006,Ding et al.2004,Ying et al.2016).Innate related inflammatory responses has long been taking part in as a critical role in the body response to infections(Wang \&Ma 2007)A supporting study demonstrate that hypercytokinemia is the principle immunopathological mechanism that contribute to severe clinical presentation of the infectious disease patients(Martinez-Ocana et al.2013).

The molecular genetic studies on hypercytokinemia paired with covid-19 severe cases have revealed that the genes that code for the principle types involved in the events of covid-19 hypercytokinemia are polymorphic with some allele association in susceptibility to an array of infection conditions ended with severe outcomes (Tufets 2008,Haqu et al.2007).Sars-cov-2 robustly trigger expression of numerous IFN individual genes which exhibit immunopathologcal potentials through gene over-representation process to the genes involved in the inflammation. The expression of proinflammatory cytokine genes ,especially those of chemokines was markedly elevated in covid-19 cases as compared to pneumonia patients an controls(Zhou et al.2020). Thus, the extensive synthesis of cytokine and chemokines in coronavirus disease was suggested to be a major factor in exacerbating lung damage and the other fatal complications(Badawi 2020)Hypercytokinemia found selective increase IL6(Tang et al.2020) and known as cytokine storm syndrome (Castelli et al.2020).

4-2-2: Hypercytokinemia Immune Features

The main features are;

- Sars-cov-2 during infection mechanisms induce cytokine gene expression and overexpression.

- Cytokine gene polymorphisms of the cytokine involved in hypercytokinemia is associated with patient susceptibility to infections.

- Lymphocyte apoptosis early in the events of hypercytokinemia renders the infected patient immune deficient and vulnerable to an array of an infectious agents.

- Excessive cytokine release lead to tissue damage in lungs, vasculature and be a marker of severity of this virus infection.

- Apparent marker of hypercytokinemia is elevated pro-inflammatory cytokines,IL6 and peripheral blood lymphopenia.

4-2-3: Workable Immune Determination Markers,

Lymphocyte Counts,IL6 detection

\section{Immune Cross-Roads Over-reactions}

5-1:Hepato,Entero And Splenocytes

5-1-1: Unrestrained Activation[ Complement System];

It is a system of proteins present in the fluid part of blood. Such a system is compose of around 30 components which are synthesized during the embryonic life in hepatocytes, enterocytes and splenocytes. The nature of the component producing cells depends on the nature of the component itself. Molecular genetic analysis of these components have shown gene polymorphism in $\mathrm{C} 3, \mathrm{C} 5, \mathrm{C} 7, \& \mathrm{C} 8$. Biochemic analysis revealed that $\mathrm{C} 3, \mathrm{C} 4, \mathrm{C} 5$ and C8 composed of more than one polypeptide chains. Some components were showing amino acid sequence structural homology. Such finding led some workers to believe that they are of common genetic lineage and evolved by gene duplication. There are three activation pathways as; classical ,lectin and alternative or properdin pathways. Complement components either free in plasma or in membrane bound forms. Tissue microenvironment signals directed the pathway towards either of activation or inhibition. The activation cascade starts with initiation then amplification and finally membrane attack, Table-2.Complement hypo or hyper activity usually associated with pathologic conditions. The deposition of complement in the affected tissues is a sign for the complement involvement in the apparent pathology of the affected tissues. Properidin function in natural[innate] immunity. Classical operate in adaptive while the lectin pathway play a role in the encapsulated and intracellular bacteria(Abbas 2015,Parslow et al.2001,Nisonoff 1982). 
Table 2. Complement Activation Pathways

\begin{tabular}{|l|l|l|l|}
\hline Process & Classical Pathway & Alternative Pathway & Lectin Pathway \\
\hline Initiation & C1 & C3 & C1-like \\
\hline Precursor Protein & C2C4 & C3FB & C2C4 \\
\hline Activation Protease & C1s & Factor D & MASP \\
\hline Activation Convertases & C3C5 & C3C5 & C3C5 \\
\hline Membrane Attack & C5,C6, C7,C8,C9 & C5,C6,C7,C8,C9 & C5,C6,C7,C8,C9 \\
\hline Cell lysis & C9 & C9 & C9 \\
\hline
\end{tabular}

The first line host immune system response to sars-cov-2 infection is the complement system. Since unrestrained contribute to acute and chronic inflammation in the infected human being leading to intravascular coagulation, cell injury and it ultimately leads to multi-organ failure and death(Moris\& Remazzi 2013). The immunochemical analysis of covid -19 dead lung tissue revealed strong staining for complement components ;MBL,C4,C3 and the terminal membrane attack complex C5b-C9(Gao et al.2020).Activated complement functions to eliminate the pathogen through opsonisation, attraction and activation of neutrophil and macrophages, and enhancing the humoral and $\mathrm{T}$ cell immune responses(Noris \&Remazzi 2013).Complement system performed a dual function as it eliminate the virus through clearance mechanisms and be protective to the host but this function was paired with an un-restrained activation of complement which results in an acute and chronic inflammation ,tissue injury and finally activate the coagulation cascade .

MBL binding to sars-cov-2 infected cells induced an enhanced C4 fragment activation and deposition demonstrating that MBL activation on virus infected cells(Magro et al.2020,Ip et al.2009). The shared end point of the C3 complement activation cascade represents the terminal pathway which acts as principal player in covid19 associated tissue inflammatory injury(Magro et al.2020,Wang et al.2015).C3b binds to either of classical, lectin or alternative pathway, $\mathrm{C} 3$ convertase forms the $\mathrm{C} 5$ convertase that cleaves into C5a \&C5b.C5a is a potent anaphylotoxin which take part in exacerbating inflammatory reactions(Huber-Lang et al.2001), and C5b participates in formation of the terminal complement components C5b-9 which insert itself within the cell membrane leading to cell injury and dysfunction.C5a promotes monocyte and neutrophil attraction, aggregation and activation to generate oxidative burst with the release of reactive oxygen species that exert a critical role in virus induced lung damage and mortality(Akaike et al.1990). The complement activation products induce tissue factor expression and the secretion of von-Willebrand factor and promote the secretion of platelet factor $\mathrm{V}$ and the assembly of functional $\mathrm{FXa} / \mathrm{FVa}$ complex(Kergala et al.2018). The activation product of $\mathrm{C} 5$ associated with vasculopathy which is supported by deposition of C5-9 in microvasculature of the intra-alveolar wall together with sars-cov-2 spike envelope and in per-tubular capillaries as well as glomerular arterioles (Magro et al.2020).

5-1-2: Immune Features:

The basic features are;

- It is a state of an over-activation of complement system.

- Induce acute and chronic inflammatory responses.

- Over-activation terminate by cell lysis, tissue injury, triggering the coagulation pathways.

- Deposition in the affected vasculature of lungs and kidneys

- Ultimately paired with multi-organ failure and death.

- The correlation of complement over-activation with hypercytokinemia and immunothrobi holds a debate position among workers.

5-1-3; Workable Determination Immune Markers

Complement and spike protein deposition in the affected tissues by immune-histochemical studies on autopsied samples ,assay complement activity in blood samples

\section{Adaptive Immune Over reactions}

\section{6-1: B lymphocyte Responses}

6-1-1:Autoimmune Phenocopy[B cell]:

B cell originated from the lymphoid progenitor of the pluripotent stem cells. So far cell variability is concerned, lymphoid cells are considered to be more variable than granulocytes and monocytes in the morpohological sense . The ratio of nucleus to cytoplasm is large. They are devoid from Golgi apparatus and the endoplasmic reticulum and own amebic movement but lower than that of granulocytes and monocytes. B cells have several types of cell surface markers. Their life span starts in the bone marrow as stem cells developed to B cells in bone marrow or migrate before maturity to spleen and other peripheral lymph nodes. Stem cell differentiated to lymphoid progenitor then to pro B and followed by pre B and finally to adult B lymphocyte. On antigenic stimulation mature B grew up, expanded and differentiated into effector and memory B cells. The nature of B cell stimulants are antigenic epitopes, lectins and lipo-poly-saachrides LPS. The mature B cell types are B1,B2 and B10.B cell functions as antibody producers, cytokine producers and antigen presenting cells.So far 
phenocopies of B cells are concerned they are; immune phenocopy, toleragenic phenocopy ,allergenic phenocopy and autoimmune phenocopy(Abbas et al .2015,Dale and Foreman 1984). B cell autoimmune phenocopy was reported in autoimmune endocrino-pathies, rheumatoid arthritis, and idiopathic conditions as well as in patients treated with interferon type I as in the followings; People bearing monogenic inborn errors of IFN gamma,IL6 and IL17A/F genes are driven to produce an autoimmune phenocopy of B cells capable to produce neutralizing autoantibodies against these cytokines(Casanova \& Abel 2020,Hoflich et al.2004,Paul et al.2010) renders them vulnerable to Mycobacteriosis and candidiasis. Type I interferons may be produced from two immune cell types. First the plasmacytoid dendritic cells and other leukocytes of innate origin and the second are produced by most if not all immune cell types that contribute in cell intrinsic immunity against viral infection (Gresser 1997,Hoffman et al.2015, deWeerd et al.2020).Virus on cell infection bind to interferon receptors on various immune cells stimulate IFN genes through phosphorylation of STAT1-STAT2-IRF9 trimer(Darnell 1997).But neutralizing IgG against IFNs may be present in patients treated with IFNalpa2 or IFNB(Vallbracht et al.1981), and exist in almost all patients with autoimmune polyendocrinopathies (Meager et al.2006) and in systemic lupus erthymatosus patients ,knowing that these patients do not seem to suffer from extra-ordinary severe viral infection(Panem et al 1982). While those patients having an inborn errors in Type I IFNs can underlie severe viral infections including that of respiratory tropism(Zhang et al.2020).Some workers have been reported, a patient with idiopathic neutralizing autoantibody against type I interferons made him suffering from severe chicken pox and shingle(Pozzetto et al.1984,Casanova\&Gresser 2019).In a study has been conducted on few patients withRAG1 or RAG2 mutations found that they produce auto antibodies against type I interferons renders them susceptible to chicken pox, viral pneumonia and other viral infections(Walter et al.2015).

Three autoimmune polyendocrinopathy patients were showing a pre-existing anti-type I interferon autoantibodies and life threatening pneumonia(Beccuti et al.2020). Bastard et al.(2020) have shown an inborn error in type I IFNs autoantibody producing B cell phenocopy render the patient immunity underlie life threatening covid-19 pneumonia in at least $10 \%$ of the study patients.

6-1-2:Immune Features:

The basic immune features are depicted in the followings;

- The inborn errors of type I interferons is a rare human genetic trait characterized by the expression of an interferon specific B cell autoimmune phenocopy.

- It was traced in poly-endocrinpathy, and SLA patients.

- It is state of pathologic autoimmune condition mostly render patients vulnerable to viral infection.

- Currently reported in association with sever sars-cov-2 infectious pneumonia.

6-1-3: Workable Immune Determination Markers;

B cell immunophenotyping ,IFN type Autoantibody detection

\section{T cell Responses}

7-1:Viral sensor T cells;

$\mathrm{T}$ cells are originated in bone marrow from the pluripotent stem cells then migrate to thymus for maturity. Though some workers holds that $\mathrm{T}$ cells originated and matured in the thymus. From the morphologic point of view T cells are similar to B cells except they differ in the nature of the surface receptors and in functions. Since T cells haven't surface Ig and contained CD2 while B cell have surface Ig and devoid of CD2.The migrated immature lymphoid cells to the thymus undergoes negative and positive selection process ended with mature $\mathrm{T}$ cells. $\mathrm{T}$ cells are ramified into an array of subsets as; Helpers ,regulators ,killers , dth and mucosal invariant. The antigenic activation of resting $\mathrm{T}$ cells established through two cellular signals , the stimulatory and the co-stimulatory signals via signal transduction process. If for any reason only one signal transduced $\mathrm{T}$ cell inters in an anergy state. The $\mathrm{T}$ cell functions in, regulation of immune responses ,stimulate B cell to produce antibody following the antigenic stimulation, cytotoxicity of viral infected cells, take part in hypersensitivity reactions and cytokine production(Abbas et al.2015,Parslow et al.2001).

$\mathrm{T}$ cells displayed a marked role in the defence against sars-cov-2 human infection(Ni et al.2020).In the sense of the immune system compartmentalization it is divided into mucosal and systemic immune system(Parslow et al.2001).Within this sense T cells are of mucosal and systemic T cells .Mucosal $\mathrm{T}$ cells have a subset known as mucosal invariant $\mathrm{T}$ cell[MAIT] which are of adaptive nature with an innate like immune function .It performs an antiviral sensor function(Godfrey et al.2015).MAIT represent 1-10\% of T cells in circulation having a strong tissue homing ability and mainly abundant in the liver and lungs(Provine \& Klenerman 2020).Riboflavin a B2 microbial metabolite processed by antigen presenting cells and presented to MAIT cells through MHCIb related protein molecules to these cells through the surface TCR recognition will activate them(Kjer-Nielsen et al. 2014)Though other MAIT functions can be activated or co-activated by IL18 and IFN cytokines(Ussher et al.2014,Lamichhane et al.2020) . MAIT cells exhibit rapid IFN, TNF-alpha and IL17 cytokine production and performed a granzyme B dependent cytotoxic function(Kurioka et al.2015,Boulous et al.2020).MAIT cells can recognize bacterial and viral metabolites and perform an innate-like sensors in which they mediate antiviral 
responses. So far the case sars-cov-2 human infection is concerned MAIT cells have shown profound preferential decline in the peripheral blood stream in severe covid-19 patients paired with the strong MAIT cell activation this was paralleled with rich existence of these cells in the airways together with IL17A pro-inflammatory cytokine bias in the airways. MAIT DC69high CXCR3low immune-pheno-types associated with poor clinical outcomes .On convalescent phase, however ,MAIT cells normalized and parallel with the dynamic recruitment to the blood and tissue(Parrot et al.2020).

7-1-2 ; Immune Features;

The apparent immune features are as in the following ;

- $\quad$ MAIT cells are mucosal adaptive immune cells with an innate immune -like antiviral activities. They represent an antiviral sensors.

- $\quad$ They have the ability to recognize bacterial and viral metabolites.

- Viral epitopes activate them to mediate antiviral responses.

- Severe covid -19 cases associated with activation of these cells with an evident migration to airways and enrichment there .Convalescent restore the cell distribution to normalization state.

- $\quad$ MAIT CD69 high-CXCR3low paired with poor patient outcomes.

7-1-3:Workable Immune Determination Markers,

MAIT immunophenotyping,MAIT counts in local and systemic compartments.

\section{Comparative Phenomenology:}

The aforementioned phenomena are traced in different; Countries ,athenic groups, socioeconomic status, contributors and attitudes. The author holds the idea that he could not expect all of these phenomena do happened in one single severe case of covid-19, Table-3. What he tried to make is a subjective logical comparison to deduce the practical use feasibility of their gold standard markers to be helpful to the patient welfare .Immunothrobi, and hypercytokinemia have shown to be appreciable in practice( Middleton et al.2020, Tang et al.2020 ) and with ease, manageable determination assays.

Table 3. Comparative Phenomenology of Immune over Reaction in Covid-19

\begin{tabular}{|c|c|c|c|c|c|c|}
\hline Phenomena & $\begin{array}{l}\text { Response } \\
\text { nature }\end{array}$ & Source cells & $\begin{array}{l}\text { Covid- } \\
\text { 19.Disease } \\
\text { gold } \\
\text { standard }\end{array}$ & $\begin{array}{l}\text { Phenomena gold } \\
\text { standard }\end{array}$ & Correlation & Reference \\
\hline $\begin{array}{l}\text { Immuno- } \\
\text { thrommbi }\end{array}$ & Innate & Neutrophils & In use & $\begin{array}{l}\text { DNA, ,myeloperoxi } \\
\text { dase-DNA.D dimer }\end{array}$ & $\begin{array}{l}\text { Possible } \\
\text { relation to } \\
\text { cytokine } \\
\text { storm }\end{array}$ & $\begin{array}{l}\text { Middleto } \\
\mathrm{n} \text { et } \\
\text { al.2020 }\end{array}$ \\
\hline Cytokine storm & Innate & $\begin{array}{l}\text { Innate } \\
\text { immune cells }\end{array}$ & In use & $\begin{array}{l}\text { Lymphopenia, } \\
\text { pro-inflammatory } \\
\text { cytokines }\end{array}$ & $\begin{array}{l}\text { Possile } \\
\text { relation to } \\
\text { microthrombi. }\end{array}$ & $\begin{array}{l}\text { Middleto } \\
\mathrm{n} \text { et } \\
\text { al.2020 }\end{array}$ \\
\hline $\begin{array}{l}\text { Unrestrained } \\
\text { activation }\end{array}$ & $\begin{array}{l}\text { Cross- } \\
\text { road }\end{array}$ & $\begin{array}{l}\text { Hepato,entro } \\
\text {,splenocytes }\end{array}$ & $\begin{array}{l}\text { Limited in } \\
\text { use }\end{array}$ & $\begin{array}{l}\text { Determination of } \\
\text { concentration, CH50 } \\
\text { Immun- } \\
\text { histchemistry }\end{array}$ & - & - \\
\hline $\begin{array}{l}\text { Autoimmune } \\
\text { phenocopy }\end{array}$ & Adapted & B cell & $\begin{array}{l}\text { Limited in } \\
\text { use }\end{array}$ & $\begin{array}{l}\text { IFN type I } \\
\text { IgG ,neutralizing } \\
\text { autoantibody } \\
\text { determination }\end{array}$ & - & - \\
\hline $\begin{array}{l}\text { Viral } \\
\text { Sensors[MAIT] }\end{array}$ & Adapted & $\mathrm{T}$ cells & $\begin{array}{l}\text { Limited In } \\
\text { use }\end{array}$ & $\begin{array}{l}\text { Cytokine, } \\
\text { immunophentyping }\end{array}$ & - & - \\
\hline
\end{tabular}

\section{Conclusion}

Five immune over reaction phenomena were frequently traced in severe sars-cov- 2 human infections. These are sharing common feature as ;i-of immune nature, ii-over reaction, and paired with severity and most of which reached normalization on proper therapy and on possible recovery. They are distributed as two for innate immune response, one for cross -road responses and two for the adapted immune responses. The innate ones are immunothrombi and cytokine storm, The cross-road was the unrestrained activation of complement system and the adapted constitute autoimmune phenocopy[IFN type I interferons] and the viral sensors [MAIT].Both of the immunothrombi and the cytokine storm have gold standard markers in the current use of covid-19 diagnosis while the other three needs facilities of advanced immunology research laboratories. 


\section{References}

Abbas,A.K.,Lichtman,A.H.\&Pillai,S.(2015).Cellular And molecular Immunology ,8th ed.ElsevierSaunders.Canada.51-170.

Akaike,T,Ando,M.,Oda,T.et al.(1990).Dependence on O2 generation by xanthine oxidase of pathogenic influenza virus infection in mice. J. Clin. .Investig.85:793-795.

Bames,B.J.,Adrover,J.M.,Baxtor-Stoltzfus,A.etal.(2020).Targeting potential derivers of covid-19 neutrophil extracellular traps.J.Exp.Med.6:e2020.0652

Bastard,P.,Rosen,L.B.,Zhang,Q.,Michailidis,E.,Hoffmann,H-H.et al.(2020). Autoantibodies against type I IFNs in patients with life threatening covid-19.Science.10.1126/science.abd4585.

Bonaventura,A.,Liborale ,L., Carbone ,F.et al.(2018). The pathophysiological role of neutrophil extracellular traps in inflammatory diseases. Thromb. Haemost. 118(1):6-27.

Beccuti,L., Ghizzoni V.,Cambria,V,,Codullo,P.,Sacchi,E.et al.(2020).A covid-19 pneumonia case report of autoimmune polyendocrine syndrome typeI in Lombardy.Italy.Letter to the editor.J.Endocrinol.Invest.43:1175-1177.

Boulouis,C.,Sia,W.R.,Gulam,M.Y.,Teo,J.Q.M.,Png,Y. T.et al.(2020).Human MAIT cell cytolytic effector proteins synergize to overcome carbapenem resistance in Escherichia coli.PLOS.Biol.18.e3000644.

Casanova,J-L.,Abel,L.(2020).The human genetic determinism of life threatening infectious diseases: genetic heterogeneity? Hum. Gent .139.681-694.

Casanova,J-L.,\& Gresser ,I.(2019).Interferon. J. Interferon .Cytokine Res.39:317-320.

Dale M.M. \&Foreman ,J.C.(1984).Textbook of Immunopharmacology .Black Well Scientific Publications.3652,93-114.

Darnell, Jr. ,J.E.(1997).STATs and gene regulation.Science.277:1630-1635.

deWeerd ,N.A .,Vivian J.P.,Lim,S.S.,Haung, U.S., Hertzog, P.J.et al.(2020). Structural integrity with functional plasticity :what type IFN polymorphism reveal.J.Leukoc.Biol.108:909-924.

Ding, Y. He ,L. ,Zhang ,Q. ,et.al.(2004).Organ distribution of severe acute respiratory syndrome(sars) associated coronavirus(sars-cov) in patients; implications for pathogenesis and virus transmission pathway .J. Pathol. 203(2).622-630.

Duque,G,A.\&Descoteaux ,A.(2014).Macrophage cytokines ;involvement in immunity and infectious diseases.Front.Immunol.5;491.

ECDPC.(2020).Diagnostic testing and screening for sars-cov-2.An.official EUwebsite.Jun.11.2020.

Figueiredo-Campos ,P ,Blankenhaus ,B .Mota ,C.,Gomes ,A.,Serrano,M .et.al.(2020).Seroprevalence of anti-sarscov-2 antibodies in covid-19 patients and healthy volunteers up to six months post disease onset.Eur.J.Immunol.21.oct.2020.doi.org/10.1002/eji.202048970.

Fuchs,A.T.,Abed,U.,Goosmann ,C .et al.(2007).Novel cell death program leading to neutrophil extracellular traps.J.Cell.Biol.176(2):231-241.

Fuchs,A.T.,Brill,A.,Duerschmied, D.et al.(2010).Extracellular $\quad$ DNA traps promote thrombosis.Proc.Natl.Acad.Sci.107(36):15880-15885.

Goa, T. ,Hu ,M. ,Zhang, X.et al.(2020).Higly pathogenic coronavirus N protein aggravate lung injury by MASP2 mediated complement activation .MedRxiv available at http/doi. org/10.1101/2020.03,29.20041962.

Godrey,D.I.,Uldrich,A.P.,McCluskey,J.,Rossjohn,J.,Moody,D.B.(2015).The burgeoning family of unconventional T cells.Nat.Immunol.16:1114-1123.

Gresser,I,(1997).Wherefore interferon?.J.Leukoc..Biolo.61:567-574.

Guan,W.J.Ni,Z.Y.,Hu,Y.et al.(2020).Clinical characteristics of coronavirus disease 2019 In china.N.E.J.Med.382:1708-1720.

Haque,A.,Hober,D.,Kasper,L.(2007).Confronting potential influenza A(H5N1) with better vaccines.Emerg.Inet.Dis.13(10):1512-1518.

He,I.,Ding,Y.,Zhang,Q.et al.(2006).Expression of elevated levels of pro-inflammatory cytokines in sars-covinfected ACE2+ cells in sars patients :relation to the acute lung injury and pathogenesis of sars .J. Pathol. $210(3): 288-297$

Hoflich,R.,Sabat,S.,Rosseau,B.Temmesfeld,H.,Slevogt,W.D.etal.(2004).Naturally occurring anti-IFNgamma autoantibody and sever infection with Mycobacteriumcheloneae and Burkholeria coronavirus.Blood.103:673-675.

Hoffmann,H-H.Schneider,W,M.,Rice,C.M.(2015).Interferons and viruses:An evolutionary arms race molecular interactions.Trends.Immunol.36:124-138.

Huang,C.,Wang,Y. Lix, et al.(2020).clinical features of patients infected with covid-19 novel coronavirus in Whuhan,China,Lancet.395:1708-1720.

Huber-Lang,M.,Sarma,V.J.,Lu,K.T.et al.(2001).Role of C5a in multi-organ failure during sepsis.J.Immunol.166:1193-1199.

Keragala,C.B.,Draxler,D.F.,McQuilten ,Z.K. et al.(2018).Haematosis and innate immunity a complementary 
relationships ,a review of the innate relationship between coagulation and complement pathways .Brit,J. Haematol.180:782-798.

Kjer-Neilsen ,L., Patel, O. ,Corbett ,A.J .,LeNours,J .,Meehan ,B.et al. (2012) .MR1 present microbial vitamin B metabolite to MAIT cell.Nature.491:717-723.

Kurioka,A.,Usshur,J,E.,Cosgrove,C.,Clough,C.,Fergusson,J.R.etal.(2015).MAIT cells are licensed through granzyme exchange to kill bacterially sensitized targets. Mucosal.Immunol.8:429-440.

Lamichhane,R.,Galvin,H.,Hannaway,R.F.,de laHarpe,S.M.,et al.(2020).Type I interferons are important costimulatory signals during T cell receptor mediated human MAIT cell activation.Eur.J.Immunol.50:178-191.

Le Bourhis,L., Martin, E., Peguillet ,I, Gulhot, A. ,FrouxN.et al.(2010) : Antimicrobial activity of mucosal invariant T cells.Nat.Immunol.11:701-708.

Magro,C.,Mulvey,J.J.,Berlin,D.(2020).Complement associated microvascular injury and thrombosis in pathogenesis of severe covid-19 infection report of five cases.Transmi.Res.220:1-13.

Mame,B.K.,Denome,F. ,Middleton ,E.A.,et al.(2020).Platelet gene expression and function in covid-19 patients .Published online head of print. Blood 20.Jan.2020.

Martinez-Ocana,,J,Olivo-Diaz, A.,Salaz-Dominguez,T.,et al.(2013).plasma cytokine levels and cytokine gene polymorphisms in Mexican patients during influenza pandemic A (H1N1)pdm09.J.Clin.Virol.58(1):108-113.

Middleton,E.A.,He,X-Y.,Denome,F.,Campbell,R.A.Ng,D.(2020).Neutrophil extracellular traps contribution to immunethrombosis in covid-19 acute distress syndrome.Blood.135:1169-1172.

Ni,L.,Ye,F.,Cheng,M.L.,Feng,Y.,Deng,Q.et al.(2020).Detection of sars-cov-2 specific humoral and cellular immunity covid-19 convalescent individuals.Immunity 52:971-977.e3.

Nisonoff,A.(1982).Introduction To Molecular Immunology .Sinauer Associate . INC.USA.

Noris, M .Remuzzi ,G.,(2013).Overview of complement activation and regulation.Semi.Nephrol.33:479-492.

Noris,M.,Bengni,A,.Remuzzi ,G.(2020). The case of complement activation in covid-19 multiorgan impact.Kidney International.98:314-322.

Panem ,S. ,Check, I.J.,Henriken,D.,Vilcek,J.(1982).Antibodies to alpha-interferon in a patient with systemic lupus erythematosus.J.Immunol.129:1-3.

Parrot,T,Gorin,J-B.,Bonzetta,A.,Maleki,K.T.,Kammann,T.et.al.(2020).MAIT activation and dynamics associated with covid-19 severity .Sci.Immuno l.101126/sciimunol.eabe1670.

Parslow,T.G.,Stitis,D.P.,Terr,A.I.,Imboden,J.B.(2001).Medical Immunology.10th ed. Chapter 14.Lange medical Books/McGraw-Hill,N.Y.

Puel,A.,Doffinger,R.,Natividad,A..,Chrabieh,M.,Barcinas-Morales, G.et al.(2010).Autoantibodies against IL17A,IL17F and IL22 in patients with chronic muco-cutaneous candidiasis and autoimmune polyendocrine syndrome type I.J.Exp.Med.207:292-297.

Pozzetto,B.,Mongensen,K.E.,Tovey,M.G.,Gresser,I.(1984).Characteristics of autoantibodies to human interferon in a patient with varicella-zoster disease.J.Infect.Dis.150:707-713. Provine,N.M.,\&Klenerman,P.(2020).MAIT in health and disease .Annu .Rev. Immunol.38:203-208.

Schonrich,G.,Raftery, M.J.(2016).Neutrophil extracellular traps go viral .Front.Immunol.7:366.

Tufet ,M.(2008).The wave behind theTGN1412 storm.Nat.Rev. Immunol. 8(5):322-323.

UssherJ.E.,Bilton,M.,Attwod,E.,Shadwell,J.,Richardson,R.et al.(2014). CD161++ CD8+ T cells including the MAIT cell subset are specifically, activated by IL12,IL18 in a TCR independent manner .Eur. J.Immunol.44:195-203.

Vallbrachi,A.,Treuner,J.Flehmig,B.,joeester,K.E.,Neithammer,D.(1981).Interferon neutralizing antibodies in a patient with human fibroblast interferon.Nature.289:496-497.

Walter,J.L.,Rosen,L.B.,Csomos,K.,Rosenberg,J.M.,Mathew,D.et al.(2015).Broad spectrum antibodies against self -antigen and cytokines in RAG deficiency,J,Clin.Invest.125:4135-4148.

Wang,R.,Xiao,H.,Guo,R,et al.(2015).The role of C5a in acute lung injury induced by highly pathogenic viral infections.Emerg.Microb.Infect.4:c28.

Wang,H.\&,Ma,S.(2008).The cytokine storm and factors determining the sequence and severity of organ dysfunction in multiple organ dysfunction syndrome .Am. J. Emerg . Med.26(6):711-715.

Xia,W.,Yaquing,D.(2020).From sars to covid-19,pathogens ,receptors, pathogenesis and principles of treatments. Clin.J.Pathol. 49:EO12. doi,1003760/cma.j.112151-2020318-00220.

Ying,T.,Li,W.,Dimitrov, D,S.(2016).Discovery of T cell infection and apoptosis by middle east respiratory syndrome coronavirus.J.Infect.Dis.213(6):877-879.

Zhang,Q.,Bastard,P.,Liu,Z.,LePen, J., Moncada-Velez ,M.et al.(2020).Inborn errors in type interferon immunity in patients with life threatening covid-19.Science.101126/scienceabd4570.doi.101126/scienceabd4570.

Zue,Y.,Valavarthi,S.,Shi,H.,Gockman,K.,Zue,M.et.al.(2020).Neutrophil extracellular traps in covid-19 patients. JCI Insight.5(11):e138999. 